\title{
Antoine Henri Becquerel (1852-1908): a scientist who endeavored to discover natural radioactivity
}

\author{
Masaru Sekiya $\cdot$ Michio Yamasaki
}

Published online: 16 October 2014

(C) Japanese Society of Radiological Technology and Japan Society of Medical Physics 2014

\section{Members of the Becquerel family}

Antoine Henri Becquerel [1] (Fig. 1) was born in Paris on December 15, 1852, in the Becquerel family, which was a family of renowned scientists. Starting with his grandfather, members of three generations of the Becquerel family were physicists, and they had an extraordinary interest in phosphorescence and fluorescence.

His grandfather, Antoine César Becquerel (1788-1878), was a member of the inaugural class of the École Polytechnique [2]. ${ }^{1}$ He joined the army during the war waged by Napoleon against Spain. After that, he became a first-generation professor in the department of applied physics of the Musée d' Histoire Naturelle [3], ${ }^{2}$ which is dedicated to scientific research. He wrote two books on phosphorescence.

His father, Alexandre Edmond Becquerel (1820-1891), started as an assistant and became a professor at the École Polytechnique. He was also a professor at the Musée d' Histoire Naturelle. He received a degree of Doctor of Science from the University of Paris. He conducted scientific research on the effect of light, and he was among those who photographed the spectrum of sunlight for the first time. Moreover, he was an authority on fluorescence and had a particularly good knowledge about uranium. He designed a phosphoroscope with which he measured the

\author{
M. Sekiya $(\bowtie)$ \\ Department of Radiological Technology, Graduate School of \\ Health Sciences, Niigata University, 2-746 Asahimachi-dori, \\ Chuo, Niigata 951-8518, Japan \\ e-mail: mseki@clg.niigata-u.ac.jp \\ M. Yamasaki \\ Hokkaido University, 2665-7 Torihara, Nishi-Ku, \\ Niigata 950-1115, Japan
}

intensity and duration of the fluorescence of uranium under various lightrays.

Antoine Henri Becquerel of the third generation entered the École Polytechnique in 1872. In 1874, he was enrolled at the École des Ponts et Chaussées and studied civil engineering for 3 years. ${ }^{3}$ For some time, he worked in the Ministry of Construction as a civil engineer, but after pursuing research as an assistant to his father, he also became a professor of applied physics at the Musée d' Histoire Naturelle in 1892. He received a degree of Doctor of Science from the University of Paris. He was also selected as a member of the Académie des Sciences, published research articles on fluorescence and phosphorescence, and joined the École Polytechnique as a professor. He became a leading scientist in the field of phosphorescence and fluorescence along with his father, and he held high-ranking positions in academic societies with his many research achievements.

\section{Discovery of unknown radiation}

In a regular meeting of the Académie des Sciences on January 20, 1896, the famous mathematician and astronomer Jules Henri Poincaré, professor at the University of Paris, circulated an X-ray photograph received directly from W. C. Röentgen among the members of the Académie

\footnotetext{
1 At that time, graduating from the École Polytechnique was a necessary condition to hold key posts in the fields of science, technology, and military. See Ref. [2] Shozo Hashimoto, 34.

2 The Musée d' Histoire Naturelle is a museum-like educational research institution formed by reorganization of Royal Botanical Gardens in 1793 after the French Revolution. See Ref. [3] Seiko Nishio, 35.

${ }^{3}$ See Ref. [3] Seiko Nishio, 34.
} 


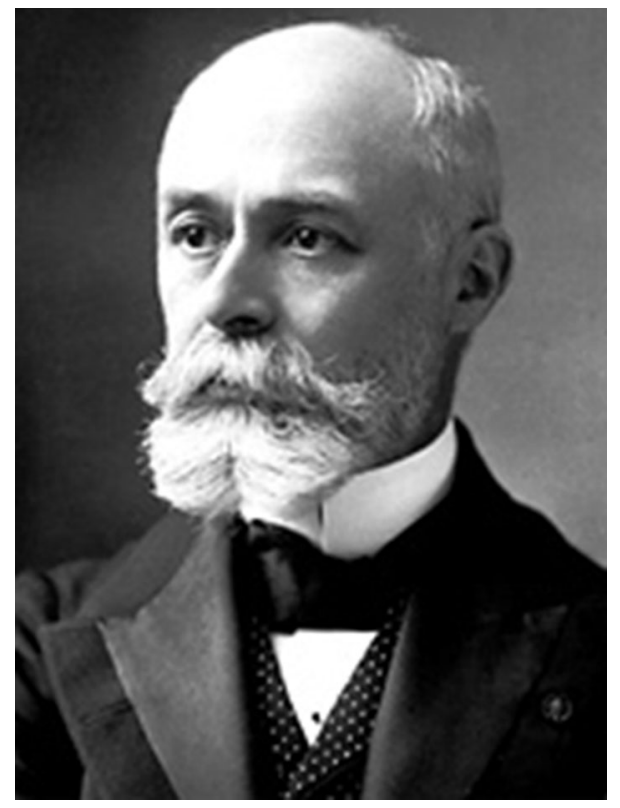

Fig. 1 Portrait of Antoine Henri Becquerel

des Sciences for their inspection. Henri Becquerel, who was present as one of the members, asked, "From which side of the discharge tube are the X-rays coming?" Poincare replied, "They seem to have been emitted from where the glass on the side opposite the negative electrode emits phosphorescence". Because Henri Becquerel knew from his father's work that uranium compounds generate phosphorescence, he thought that X-ray-like radiation might be emitted by strongly phosphorescent substances.

As a phosphorescent substance, Henri Becquerel used a thin section of a uranium-potassium double sulfate crystal $\mathrm{K}(\mathrm{UO}) \mathrm{SO}_{4}+\mathrm{H}_{2} \mathrm{O}$, which was placed over a photosensitive plate made from gelatin and silver bromide wrapped in two layers of thick black paper without exposing it to sunlight. Then, he exposed the whole package to sunlight for several hours. When the plate was subsequently developed, a shadow of the phosphorescent substance was seen. In a regular meeting of the Académie des Sciences on February 24, 1896, he presented a lecture on "Radiation produced by phosphorescence".

To confirm that $\mathrm{K}(\mathrm{UO}) \mathrm{SO}_{4}+\mathrm{H}_{2} \mathrm{O}$ is highly phosphorescent, Henri Becquerel wrapped a new photosensitive plate in an opaque black cloth. Then he prepared several crystalline samples with their one side covered by an aluminum plate. He had planned to develop the plates after exposing the samples to sunlight. However, on February 26 and 27, 1896, the weather in Paris was cloudy, and the experiment was stopped in the middle. The experimental sample had been left in the dark in the drawer of a table. That year was a leap year; and February 29 and March 1 were also cloudy days. However, he hurried to develop the

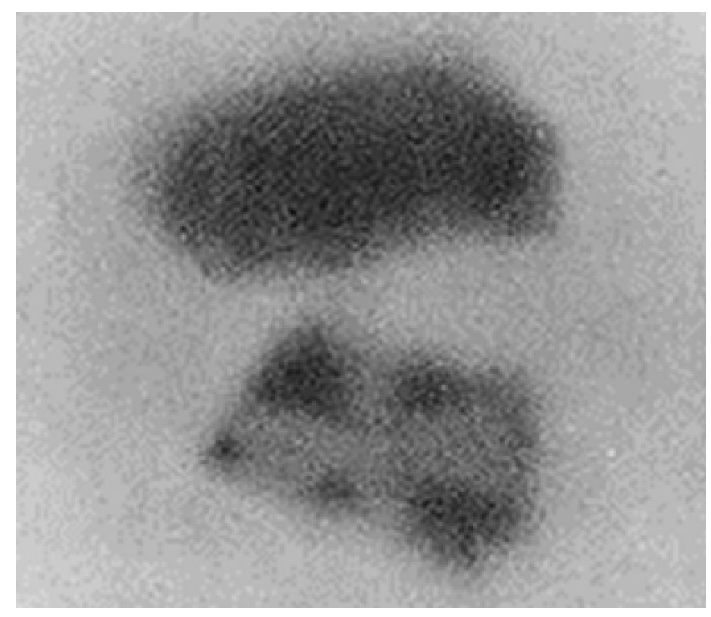

Fig. 2 An image of uranium crystalline samples recorded on a photosensitive plate, which provided clear evidence in support of invisible radiation emitted by a phosphorescent substance

plates for the meeting of the Académie des Sciences. Then, contrary to his expectation, an image (Fig. 2) of the phosphorescent substance, clearer than that in the earlier experiment, was seen even with little exposure to sunlight. From this, he came to the conclusion that the experimental sample emitted a type of radiation similar to X-rays. In the meeting of the Académie des Sciences on March 2, he reported on "Invisible radiation emitted by a phosphorescent substance".

Henri Becquerel demonstrated that an "unknown radiation" different from phosphorescence is emitted by uranium salts. He continued to present a series of research reports: the second on March 2, the third on March 9, the fourth on March 23, and the fifth on March 30 [4]. ${ }^{4}$ In these reports, he conducted experiments with other fluorescent substances such as zinc sulfide and cadmium sulfide, and he confirmed that the "unknown radiation" was a property peculiar to uranium. Supposing that a radiation different from $\mathrm{X}$-rays is emitted by uranium, he named the "unknown radiation" Becquerel radiation. Because Becquerel radiation could not produce images of the human body as could $\mathrm{X}$-rays, no one took notice of it for some time [5].

However, his discovery of Becquerel radiation created a clue that led Pierre and Marie Curie to their discovery, about 2 years later, that there are substances other than uranium that give out similar radiation. That is, the Curies discovered polonium and radium, which emit even stronger

\footnotetext{
${ }^{4}$ Becquerel had reported research on uranium through the ninth research article. He conducted research by using not only uranium compounds, but by using pure uranium metal borrowed from Henri Moissan (recipient of 1906 Nobel Prize for Chemistry), who was successful in producing uranium metal. See Ref. [4] Sakae Shimizu, 6.
} 
radiation than uranium, and they coined the technical term "radioactivity".

Henri Becquerel presented 10 reports $^{5}$ at the Académie des Sciences from 1899 to 1900 regarding radiation from radium. Because he carried radium purified by the Curies in his pocket, he was the first to suffer skin burn from the exposure. This suggested that the biological effect of radium could be used for suppressing tumors. ${ }^{6}$

\section{Nobel Prize for physics}

Henri Becquerel received the Nobel Prize for physics in 1903 "for his discovery of spontaneous radioactivity". At the same time, half of the prize for that year was conferred on the Curies. He attended the award ceremony to receive the award with his own hands and delivered the Nobel lecture on December 11. In addition to the Nobel Prize, he received other awards such as the Bernard Award, and Helmholtz Award; and in 1900, the Légion d' Honneur decoration was conferred on him.

Henri Becquerel was elected as Vice chairman of the Académie des Sciences in 1906 and its Chairman in 1908. On August 25, 1908, he died of cardiac arrest at the early age of 55 in Bretagne, in western France.

His discovery of radioactivity (Becquerel radiation) was not an outcome of mere coincidence. It was entirely due to the scientific spirit inherent in the Becquerel family and his own great talent. Furthermore, Henri Becquerel's son, Jean Becquerel (1878-1953) from the fourth generation also graduated from the École Polytechnique and later became a professor at the Musée d' Histoire Naturelle, and he too was selected as a member of the Académie des Sciences. He conducted research on the theory of relativity, radioactivity, and phosphorescence in supercooled matter. The Becquerel family was a prominent family that contributed greatly to the scientific community of France over four generations.

\section{References}

1. Yamasaki M. Sievert and Becquerel, Daikisha, Niigata. 2012; 73-92.

2. Hashimoto S. Commemorative lecture for the Centennial of the discovery of Becquerel radiation. Shin-iryo. 1996;23(6):32-35.

3. Nishio S. Physics of the 20th century started this way. Shokabo, Tokyo. 1997;29-36.

4. Shimizu S. Henri Becquerel, Antoine-Henri Becquerel (18521908) discovery of radioactivity (1896) centenary year, Japan Radioisotope Association. 1996;1-12.

5. Ōba S. Centennial of the discovery of radium Marie Curie and Pierre Curie. Nichi-Doku Iho. 1998;43(4):97-123.

\footnotetext{
5 See Ref. [4] Sakae Shimizu, 7.

${ }^{6}$ See Ref. [2] Shozo Hashimoto, 34.
} 